\title{
Regulation and perturbation of testicular functions by vitamin A
}

\author{
Gabriel Livera, Virginie Rouiller-Fabre, Catherine Pairault, \\ Christine Levacher and René Habert*
}

Université Paris 7, Tour 33/43, Box 7126, 2 Place Jussieu, 75251 Paris Cedex 05, France

\begin{abstract}
In addition to playing a fundamental role in very diverse processes such as vision and the growth and differentiation of numerous types of cell, vitamin A (retinol) and its principal biologically active derivative, retinoic acid, are clearly involved in the regulation of testicular functions in rodents. An excess of vitamin A leads to testicular lesions and spermatogenetic disorders, and a deficiency induces early cessation of spermatogenesis and adversely affects testosterone secretion. Furthermore, mice mutant for retinoic acid $\alpha$ receptors and retinoid $X \beta$ receptors are sterile. Retinoids appear to exert an action on the three main testicular types of cell (Sertoli, germinal and Leydig cells), as they act on the signalling pathways and Sertoli cell metabolism, and modify numerous factors secreted in Sertoli cells. Retinoids also appear to be necessary for the proliferation and differentiation of A spermatogonia, and for spermiogenesis. In addition, vitamin A deficiency leads to atrophy of the accessory sex organs after decreased testosterone production. Recent studies have shown that retinoids already affect these three types of cell in fetuses. Curiously, the effects of retinoids on fetal and adult testis seem opposed.
\end{abstract}

Deficiency or excess of vitamin A or retinol is frequent in humans. Severe vitamin A deficiency can be observed in most developing countries (Mora et al., 1998) and affects mainly children and pregnant women, whose needs for retinol are great (Gerster, 1997). In the industrialized countries, severe hypovitaminosis $A$ is rarely found, but an insufficient nutritional intake of vitamin $\mathrm{A}$ has been reported in $20-25 \%$ of adult women in a study of the Paris region (Hercberg et al., 1994). Conversely, hyper-retinoidaemia is frequently provoked for therapeutic purposes, as high doses of retinoids are used to treat skin diseases and several types of cancer, including cancers of the lung, kidney, skin and blood cells (Dragnev et al., 2000). Oral retinoids such as tretinoin, isotretinoin or etretinate, designed to treat skin diseases such as severe acne and psoriasis, were available between the early 1980s and 1990s and the compliance of pregnancy avoidance policies after the end of treatments with these drugs has not always been respected. The first children born to women treated with these synthetic retinoids are reaching reproductive age but, as yet, no studies have been performed to investigate the effects of these treatments, which greatly increased the concentrations of retinoids sometimes for several months after the end of the treatment, on the fertility of this generation.

A normal diet should provide sufficient dietary vitamin A through the consumption of animal fat, eggs, butter and coloured fruit and vegetables containing beta-carotenes. Moreover, other products such as milk and cereals are

*Correspondence

Email: habert@paris7.jussieu.fr artificially supplemented with vitamin A. The use of multivitamin supplements, particularly by women, is also common in the industrialized countries. These cumulative vitamin A intakes may increase retinol above recommended concentrations in subclasses of the population.

Although no study has yet been conducted to evaluate the importance of an alteration in vitamin $A$ and retinoid intake in the development and maintenance of testicular functions in men, it has long been known that retinolaemia in rats and mice is involved in testicular functions but has no effect on ovarian functions. An excess of vitamin A causes testicular lesions and spermatogenetic disorders (Lamano Carvalho et al., 1978). However, vitamin A deficiency induces early cessation of spermatogenesis (Wolbach and Howe, 1925), characterized by degeneration of all the meiotic germ cells (Thompson et al., 1964; Morales and Griswold, 1987) and defective secretion of testosterone (Appling and Chytil, 1981), and can be compensated for by dietary vitamin A supplementation or injection of high doses of retinoic acid, the active metabolite of vitamin A (Thompson et al., 1964; Appling and Chytil, 1981; Van Pelt and de Rooij, 1991).

Over the last 10 years, many studies have improved our knowledge of the location of retinoic acid receptors, the identification of their target genes and the involvement of retinoids in testicular development. The aim of this review is to present a synthesis of current knowledge on this question.

\section{Retinoid acid receptors}

Retinoic acid receptors belong to the superfamily of nuclear receptors of steroid and thyroid hormones, and include two 
Table 1. Localization of retinoic acid receptors (RARs) and retinoid X receptors (RXRs) in fetal, neonatal and adult testis

\begin{tabular}{|c|c|c|c|}
\hline & Fetal testis & Neonatal testis & Adult testis \\
\hline Sertoli cells & $R A R \beta^{3} ; R A R \gamma^{3} ; R X R \gamma^{2}$ & $\begin{array}{l}\mathrm{RAR} \alpha^{4} ; \mathrm{RAR} \beta^{4} ; \mathrm{RAR} \gamma^{2} ; \\
\mathrm{RXR} \alpha^{2,4} ; \mathrm{RXR} \gamma^{2,4}\end{array}$ & $\begin{array}{l}\text { RAR } \boldsymbol{\alpha}^{1,2,4} ; \mathrm{RAR} \boldsymbol{\beta}^{2,4} ; \mathrm{RAR} \boldsymbol{\gamma}^{2,4} ; \mathrm{RXR} \alpha^{2,4} ; \\
\mathbf{R X R} \boldsymbol{\beta}^{2,4,5,6} ; \mathrm{RXR} \boldsymbol{\gamma}^{2,4}\end{array}$ \\
\hline Germ cells & $\begin{array}{l}\text { Gonocytes: RAR } \alpha^{2,3} ; \operatorname{RAR} \beta^{2,3} ; \\
\text { RAR } \gamma^{3} ; \operatorname{RXR} \alpha^{2} ; \operatorname{RXR} \gamma^{2}\end{array}$ & $\begin{array}{l}\text { Gonocytes: RAR } \alpha^{2} ; R A R \beta^{2,4} ; \\
\text { RAR } \gamma^{2} ; \operatorname{RXR} \alpha^{2,4} ; \operatorname{RXR} \beta^{2,5} ; \operatorname{RXR} \gamma^{2,4}\end{array}$ & $\begin{array}{l}\text { Spermatogonia, spermatocytes and } \\
\text { spermatids: } \mathbf{R A R} \boldsymbol{\alpha}^{1,2,4} ; \operatorname{RAR} \beta^{2,4} ; \\
\text { RXR } \alpha^{2,4} ; \operatorname{RXR} \boldsymbol{\gamma}^{2,4,5} \\
\text { Spermatozoa: none }{ }^{1,4,5}\end{array}$ \\
\hline Leydig cells & $\begin{array}{l}\text { RAR } \alpha^{2,3} ; \mathrm{RAR} \beta^{2,3} ; \mathrm{RAR} \gamma^{3} ; \\
\mathrm{RXR} \alpha^{2} ; \mathrm{RXR} \beta^{2} ; \mathrm{RXR} \gamma^{2}\end{array}$ & $\begin{array}{l}\mathrm{RAR} \alpha^{2} ; \mathrm{RAR} \beta^{2,4} ; \mathrm{RAR} \gamma^{2} ; \mathrm{RXR} \alpha^{2,4} ; \\
\mathrm{RXR} \beta^{2,4} ; \mathrm{RXR} \gamma^{2,4}\end{array}$ & $\begin{array}{l}\mathrm{RAR} \gamma^{2,4} ; \mathrm{RXR} \alpha^{2,4,5} ; \\
\mathbf{R X R} \boldsymbol{\beta}^{2,4,5} ; \mathrm{RXR} \gamma^{2,4,5}\end{array}$ \\
\hline
\end{tabular}

Receptors the knockout of which induces sterility of testicular origin are shown in bold.

References: ${ }^{1} \mathrm{Akmal}$ et al., 1997; ${ }^{2}$ Boulogne et al., 1999; ${ }^{3}$ Cupp et al., 1999; ${ }^{4}$ Dufour et al., 1999; ${ }^{5}$ Gaemers et al., $1998 ;{ }^{6}$ Kastner et al., 1996.

main families: retinoic acid receptors (RARs) that bind all-trans and 9-cis retinoic acid isomers, and retinoid $X$ receptors (RXRs) that preferentially bind the 9-cis isomer (for a review, see Giguère, 1994). Each family comprises three classes, $\alpha, \beta$ and $\gamma$, encoded by different genes. RAR can heterodimerize with the RXR or with other nuclear receptors to act specifically on the retinoic acid response elements and activate the transcription of target genes. RXR can homodimerize or heterodimerize with other transcription factors to bind specific DNA response elements.

The six classes of receptor have been located in rats and mice by immunohistochemistry or in situ hybridization in the different types of cell of the fetal, immature and adult testis (Huang et al., 1994; Kastner et al., 1996; Akmal et al., 1997; Gaemers et al., 1998a; Boulogne et al., 1999; Cupp et al., 1999; Dufour and Kim, 1999).

In the fetal or neonatal testis (Table 1$)$, the gonocytes express the three RAR classes $(-\alpha,-\beta$ and $-\gamma)$, as well as the RXR- $\alpha$ and $-\gamma$ classes, but this expression changes throughout development and the location of the receptors is often cytoplasmic (Boulogne et al., 1999; Cupp et al., 1999). Immature Sertoli cells, which unlike adult Sertoli cells are mitotically active, express only RAR- $\beta$ and $-\gamma$ and RXR- $\alpha$ and - $\gamma$ ( Boulogne et al., 1999); however, Dufour and Kim (1999) showed that immature Sertoli cells express RXR- $\alpha$ and $-\gamma$ and also RAR- $\alpha$ and $-\beta$ but no RAR- $\gamma$. This discrepancy may have occurred because of the use of different antibodies. Fetal Leydig cells, which form a generation of cells distinct from adult Leydig cells, express all three classes of RAR (Boulogne et al., 1999; Cupp et al., 1999) and all three classes of RXR (Boulogne et al., 1999).

In the adult testis (Table 1), four classes of receptor have been identified in the germ cells: RAR- $\alpha$ and $-\beta$ and RXR- $\alpha$ and - $\gamma$ (Kastner et al., 1996; Akmal et al., 1997; Gaemers et al., 1998a; Dufour and Kim, 1999). RAR- $\alpha$ is expressed essentially from the spermatocyte to the spermatid stage in the course of elongation, whereas RAR- $\beta$ is expressed earlier, from the spermatogonia to the round spermatid stage. RXR- $\alpha$ and $-\gamma$ are expressed at all these stages. The haploid germ cells no longer express any retinoic acid receptor from the elongated spermatid stage onwards. The adult Sertoli cells express all six classes of retinoic acid receptor, and the Leydig cells express all classes except RAR- $\alpha$ (Akmal et al., 1997).

Thus, the distribution of retinoic acid receptors in the testis is very complex and often redundant, and depends not only on the type of cell but also on the stage of testicular differentiation and the spermatogenic stage. In addition, these receptors are sometimes located in the cytoplasm and are therefore inactive (Boulogne et al., 1999; Dufour and Kim, 1999). The receptors may be transported into the nucleus in the presence of retinoic acid or according to other signals (Akmal et al., 1997). Thus, for example, in the Sertoli cells, the nuclear location of RAR- $\alpha$ can be induced by retinoic acid and blocked by the action of FSH (Braun et al., 2000). Similarly, the expression of retinoic acid nuclear receptors is not constant and may be subject to different types of regulation. In particular, in the testis of vitamin A-deficient animals, retinol increased the expression of RAR- $\alpha$ mRNA (Kim and Griswold, 1990; Akmal et al., 1998) without changing the concentration of RAR- $\beta$ mRNA (Kim and Griswold, 1990). Retinoic acid increases the expression of RAR- $\beta$ (Gaemers et al., 1997). These findings imply a complex model of signalling. However, only mice mutant for RAR- $\alpha$ or for RXR- $\beta$ were rendered sterile by defective testicular functions (Lufkin et al., 1993; Kastner et al., 1996), indicating that these are probably the two most essential receptors.

Finally, the transcriptional activity of retinoid acid nuclear receptors may be modulated by interaction with other proteins acting as co-activators or co-repressors. These factors appear to act by modifying the acetylation of DNA histones, thus modifying the structure of chromatin and thereby preventing transcription. Many of the coactivators have histone acetyl transferase activity, whereas co-repressors either have histone deacetylase activity or are associated with other proteins that have histone deacetylase activity. In the absence of a ligand, the heterodimer RAR-RXR might be associated with a co-repressor such as the silencing mediator for retinoic acid and thyroid hormone receptors or the nuclear receptor co-repressor (Bernardini et al., 1997; Leo et al., 2001). Receptor activation 


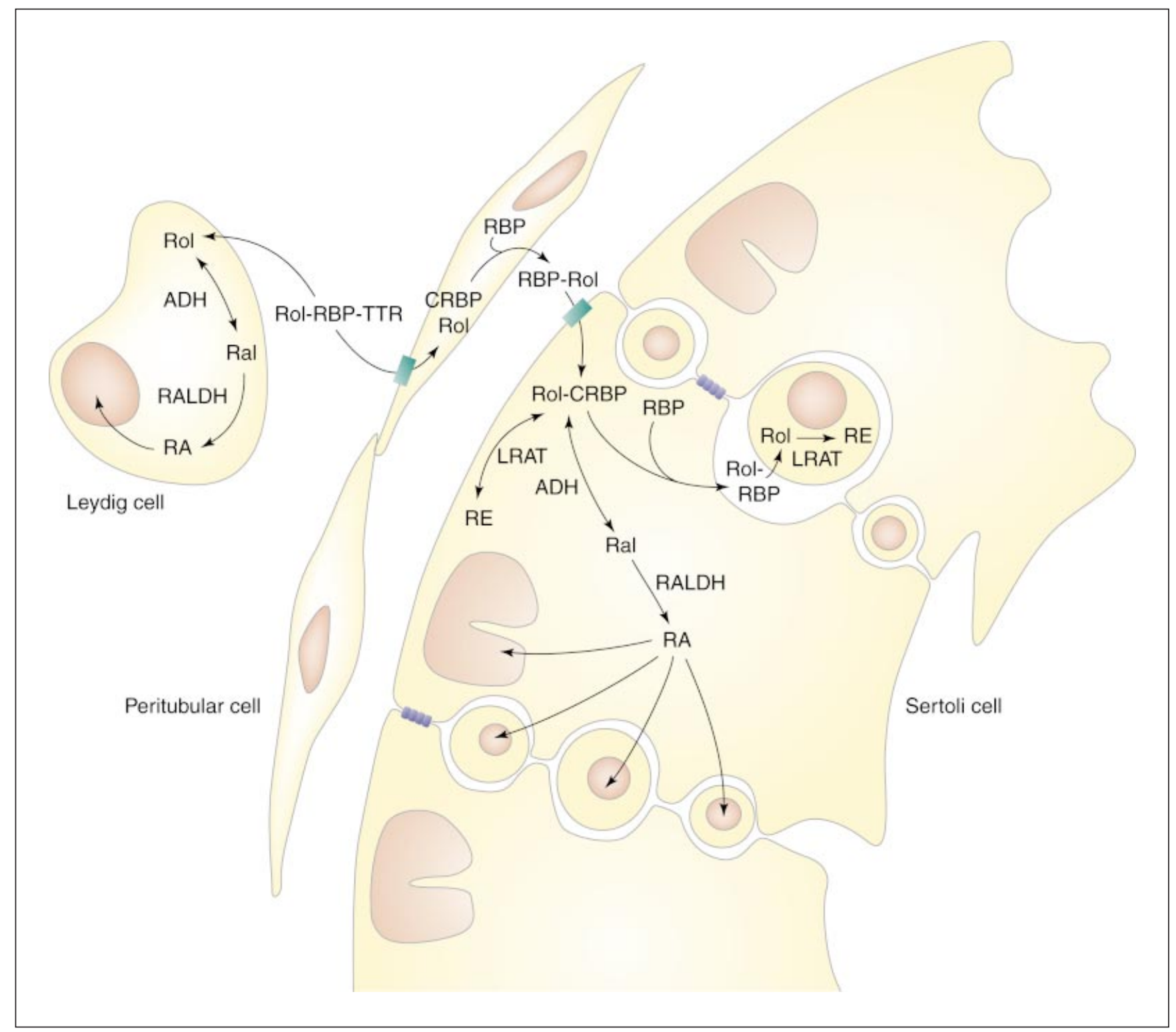

Fig. 1. Retinol metabolism in the adult testis. Circulating retinol (Rol) is bound to retinol binding protein (RBP), which is complexed with transthyretin (TTR). Retinol is internalized in the peritubular cells and then redistributed to the Sertoli cells. The Sertoli cells oxidize retinol into retinoic acid (RA) for their own needs and the needs of the germ cells, and also store retinol in the form of retinyl esters (RE). ADH: alcohol dehydrogenase; RALDH: retinal dehydrogenase; CRBP: cellular retinol binding protein; LRAT: lecithin-retinol acyltransferase; Ral: retinaldehyde.

by retinoic acid may dissociate the co-repressor complex and induce the recruitment of co-activators such as the steroid receptor co-activator 1 , receptor-associated coactivator, cellular retinol-binding protein (CRBP) or thyroid hormone receptor-interacting protein (Bernardini et al., 1997; Leo et al., 2001). There may be a third category of coregulators acting as repressors on receptors bound to their ligand, as is the case for the receptor-interacting protein (Wei et al., 2001). Unfortunately, in the testis, the expression of all these co-activators and co-repressors and their interaction with retinoid receptors is poorly documented.

\section{Metabolism of retinol in the testis}

It was thought that retinol exerts action in the testis but that retinoic acid exerts none (Thompson et al., 1964). Injection of physiological doses of retinol, and not of retinoic acid, does restore normal spermatogenesis in vitamin A-deficient rats. However, Van Pelt and de Rooij (1991) showed that 


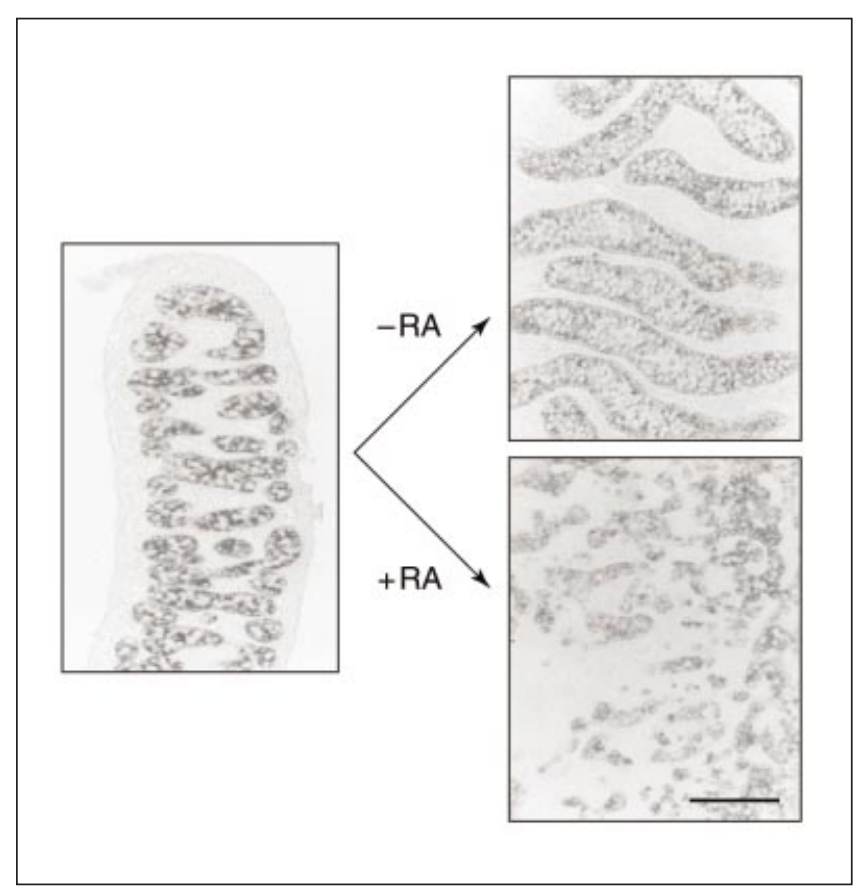

Fig. 2. Effect of retinoic acid (RA) on the organization of the seminiferous cords in testis of rat fetus. A fetal testis was explanted at day 14.5 after conception and cultured for 3 days in the absence or presence of $10^{-6} \mathrm{~mol}$ retinoic acid $\mathrm{I}^{-1}$. At the time of explantation (14.5 days after conception) and after culture $(14.5+3.0$ days), Sertoli cells were identified by immunolocalization of anti-Müllerian hormone. Scale bar represents $100 \mu \mathrm{m}$.

spermatogenesis can be re-initiated by retinoic acid, provided that it is injected repeatedly at very high doses, indicating that the blood-testis barrier inhibits the passage of retinoic acid circulating towards the germ cells, and that the Sertoli cells synthesize retinoic acid from circulating retinol. This contention is supported by the fact that the passage of radioactive retinoic acid into the testis is inhibited compared with the passage of retinoic acid into other tissues (Kurlandsky et al., 1995).

It is now known that the stages of the testicular retinoid metabolism are complex and involve different types of cell (Fig. 1). The first step in this metabolism takes place in the peritubular cells, which contain large quantities of CRBP, an intracellular protein that binds retinol with a high affinity (Blaner et al., 1987). The peritubular cells take up the circulatory retinol bound to other transport proteins, such as retinol binding protein (RBP) and transthyretin (TTR), and secrete it as a complex formed with a new RBP, in the direction of the Sertoli cells (Davis and Ong, 1995).

CRBP is also present in Sertoli cells and its expression varies according to the stage of the cycle of the seminiferous epithelium, indicating that the need for retinol depends on the type of germ cells present (Blaner et al., 1987; Schmitt and Ong, 1993). Sertoli cells are the main site of retinoic acid synthesis (Cavazzini et al., 1996). Thus, the enzymes allowing retinol oxidation into retinoic acid (alcohol dehydrogenase and retinal dehydrogenase) are essentially located in the Sertoli cells (Deltour et al., 1997; Zhai et al., 2001). These cells may then 'distribute' the retinoic acid to their neighbours, notably to germ cells. Furthermore, production of retinol acid by Sertoli cells increases during testicular development. Sertoli cells are also the main site of retinol storage. They express lecithin-retinol acyltransferase (LRAT), which allows the esterification of retinol (Cavazzini et al., 1996). FSH and retinoic acid increase retinol storage in the form of retinyl esters in Sertoli cells but retinol oxidation to retinoic acid is reduced by retinoic acid and increased by FSH (Guo et al., 2001). However, the germ cells may themselves store retinol in the form of retinyl ester, because they also express LRAT, especially at the spermatid stage (Schmitt and Ong, 1993), and may also synthesize their own retinoic acid.

Leydig cells also express the enzymes necessary to convert retinol into retinoic acid (alcohol dehydrogenase $(\mathrm{ADH})$ and retinal dehydrogenase) (Deltour et al., 1997; Lopez-Fernandez and del Mazo, 1997; Hardy et al., 2000; Zhai et al., 2001). Several of the enzymes of retinoic acid metabolism may actually be using androgens as substrates in the testis (Hardy et al., 2000).

Also present in the testis are cellular retinoic acid binding protein types I and II (CRABP), which bind retinoic acid to facilitate its transport to the nucleus or its catabolism in the different types of testicular cell, except for the peritubular cells (Blaner et al., 1987; Faraonio et al., 1993; Zheng et al., 1996). However, these proteins do not appear to be essential because animals mutant for the two types of CRABP are normal in their development, fertility, lifespan and general behaviour (Lampron et al., 1995).

\section{Retinoids and testicular development}

Retinoic acid causes disruption of the seminiferous cords in the testis of rat fetuses (Marinos et al., 1995; Cupp et al., 1999; Livera et al., 2000) (Fig. 2) and also has numerous other effects on testicular development (Table 2). Cupp et al. (1999) showed that retinoids increased transcription of the three isoforms of transforming growth factor $\beta$ (TGF- $\beta$ ) in cultured neonatal testicular cells.

Our group used an organotypic culture system to show that retinoic acid inhibits the stimulatory effect of $\mathrm{FSH}$ on the production of cAMP in rat Sertoli cells during fetal and neonatal life. The use of selective synthetic analogues of the different RAR and RXR revealed that this effect involves RAR- $\alpha$ (Livera et al., 2001). Furthermore, after birth, retinoic acid increases the proliferation of Sertoli cells via RAR- $\beta$ (Livera et al., 2001) as well as their production of transferrin (G. Livera, unpublished).

Retinoic acid diminishes the proliferation of fetal and neonatal gonocytes by acting on both apoptosis and mitosis via the activation of RAR- $\alpha$ (Boulogne et al., 1999; Livera et al., 2000, 2001; B. Boulogne, unpublished). The knockout of RAR- $\alpha$ led to an increase in the number of germ cells in mouse fetuses and neonates, indicating the involve- 
Table 2. Principal effects of retinoids on testicular cells

\begin{tabular}{|c|c|c|c|}
\hline & \multicolumn{3}{|c|}{ Testis } \\
\hline & Fetal & Neonatal & Adult \\
\hline Sertoli cells & $\begin{array}{l}\downarrow \text { Organization of } \text { cords }^{1-3} \\
\uparrow \text { Transferrin }^{4} \\
\downarrow \text { cAMP response to } \mathrm{FSH}^{3}\end{array}$ & $\begin{array}{l}\uparrow \text { Mitosis }^{3} \\
\uparrow \text { Transferrin }^{4} \\
\downarrow \text { cAMP response to FSH }^{3} \\
\uparrow \text { TGF- } \beta \mathrm{s}^{1}\end{array}$ & 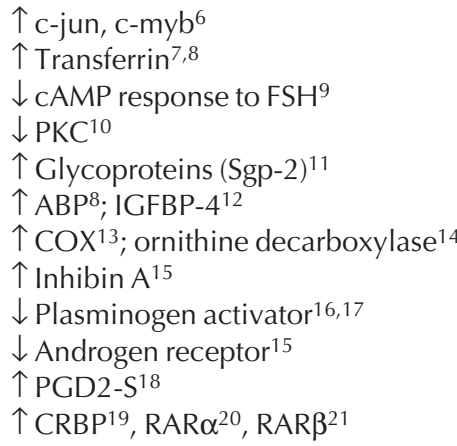 \\
\hline Germ cells & $\begin{array}{l}\downarrow \text { Gonocytes }^{3,5} \\
\uparrow \text { Mitosis } \\
\uparrow \text { Apoptosis }\end{array}$ & $\downarrow$ Gonocytes $^{5}$ & $\begin{array}{l}\uparrow \text { Spermatogonia proliferation }{ }^{22} \\
\uparrow \text { Spermatid elongation }^{23}\end{array}$ \\
\hline Leydig cells & $\downarrow$ Basal testosterone secretion ${ }^{3}$ & Without relevant effect & $\begin{array}{l}\uparrow \text { Basal testosterone secretion }{ }^{24} \\
\uparrow \text { StAR }^{25} \\
\uparrow \mathrm{P}^{25} \mathrm{OC} 17^{26} \\
\downarrow 3 \beta \mathrm{HSD}^{26} \\
\downarrow \mathrm{LHR}^{26}\end{array}$ \\
\hline
\end{tabular}

Abbreviations: TGF- $\beta$ : transforming growth factor $\beta$; PKC: calcium-dependent protein kinase; ABP: androgen-binding protein; IGFBP: insulin-like growth factor-binding protein; COX: cytochrome $c$ oxidase; PGD2-S: prostaglandin D2 synthetase; StAR: steroidogenic acute regulatory protein; P450C17:

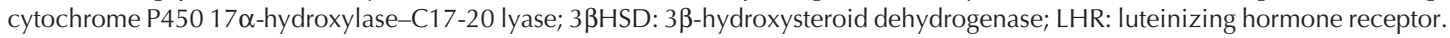

References: ${ }^{1}$ Cupp et al., 1999; ${ }^{2}$ Marinos et al., 1995; ${ }^{3}$ Livera et al., 2000; ${ }^{4} \mathrm{G}$. Livera, unpublished; ${ }^{5}$ Boulogne et al., $1999 ;{ }^{6}$ Page et al., $1996 ;{ }^{7}$ Sigillo et al., 1999; ${ }^{8}$ Skinner et al., 1989; ${ }^{9} \mathrm{Galdieri}$ and Nistico, $1994 ;{ }^{10} \mathrm{Galdieri}$ et al., 1986; ${ }^{11} \mathrm{Guma}$ and Bemard, $1994 ;{ }^{12}$ Bardi et al., $1999 ;{ }^{13} \mathrm{Gaemers}$ et al., 1998 ; ${ }^{14}$ Klamt et al., 2000; ${ }^{15}$ Zhuang et al., 1997; ${ }^{16}$ Rosselli and Skinner, 1992; ${ }^{17}$ Canipari and Galdieri, 2000; ${ }^{18}$ Samy et al., 2000; ${ }^{19}$ Eskild et al., $1988 ;{ }^{20}$ Kim and Griswold, 1990; ${ }^{21}$ Gaemers et al., 1997; ${ }^{22}$ Gaemers et al., 1998; ${ }^{23}$ Huang and Marshall, 1983; ${ }^{24}$ Chaudhary et al., 1989; ${ }^{25}$ Lee et al., $1999 ;{ }^{26}$ Lefevre et al., 1994.

ment of the RAR- $\alpha$ receptor in the control of fetal gametogenesis, and implying that, in mice, circulating concentrations of retinoids exert a negative physiological effect on the onset of the germinal line (G. Livera, unpublished).

In rats, retinoids also reduced basal secretion of testosterone in fetal Leydig cells during differentiation of these cells (Livera et al., 2000). However, in the presence of high doses of $\mathrm{LH}$ or hCG, retinoids stimulated testosterone secretion (G. Livera, unpublished). The moderate vitamin A deficit results in increased testicular steroidogenesis during fetal and neonatal life, showing that circulating concentrations of retinol exert a physiological inhibitory effect on the development of the endocrine function of the testis in rats (G. Livera, unpublished).

\section{Retinoids and Sertoli cell functions}

Retinoids are involved in the control of numerous functions in adult Sertoli cells (Table 2), the best documented of which is Sertoli cell secretion. Retinoids increase the secretion of transferrin, androgen-binding protein (ABP), insulinlike growth factor-binding protein 4 (IGFBP-4), inhibin $\alpha$ and glycoproteins, especially sulphated glycoprotein (Sgp-2), but inhibit the secretion of plasminogen activator and oestrogens in response to FSH (Rosselli and Skinner, 1992; Galdieri and Nistico, 1994; Guma and Bernard, 1994; Zhuang et al., 1997; Gaemers et al., 1998b; Bardi et al., 1999; Sigillo et al., 1999). Retinoids also act on the signalling pathways in Sertoli cells, reducing the expression of protein kinase C and of the androgen receptor, as well as the production of CAMP in response to FSH (Galdieri et al., 1986; Galdieri and Nistico, 1994). In addition, retinoids stimulate the expression of certain transcription factors, such as c-jun and c-myb (Page et al., 1996), and increase Sertoli cell metabolism, as they increase the expression of ornithine decarboxylase and cytochrome $c$ oxidase (COX) (Gaemers et al., 1998b; Klamt et al., 2000). Retinoids are also involved in controlling Sertoli cell lipid metabolism, as shown by the accumulation of lipids in the tubules of RXR- $\beta$ mutant mice (Kastner et al., 1996). Curiously, lipid accumulation was also observed in the Sertoli cells of rats with hypervitaminosis A (Biswas and Deb, 1965).

Retinoids can also modulate their own signalling pathway in the testis, as they increase the expression of CRBP, RAR- $\alpha$ and RAR- $\beta$ and prostaglandin D2 synthetase (Eskild et al., 1988; Kim and Griswold, 1990; Faraonio et al., 1993; 
Gaemers et al., 1997; Akmal et al., 1998; Samy et al., 2000). Prostaglandin D2 synthetase, which has a high affinity for retinoic acid and retinol, also serves as a retinoid transporter and is strongly expressed in the blood-testis barrier (Samy et al., 2000).

The basement membrane, which is partly secreted by the peritubular cells, may alter the activity of Sertoli cells by modifying the availability of growth factors. Retinoids may affect the synthesis and deposition of extracellular matrix components through the peritubular cells, for instance by altering the synthesis and secretion of laminin and fibronectin (Ricci et al., 1999).

The interactions between retinoids and $\mathrm{FSH}$, the main regulatory hormone in Sertoli cell functions, are complex. Like retinoic acid, FSH stimulates the secretion of transferrin, ABP and inhibin $\alpha$ (De Jong, 1988; Skinner et al., 1989) and the synthesis of retinyl esters (Guo et al., 2001). However, retinoic acid inhibits the transduction pathway of FSH by blocking the production of CAMP as well as all the activities dependent on it, such as aromatase activity and the secretion of tissue-specific plasminogen activator. In return, FSH reduces the expression of RAR- $\alpha$ (Braun et al., 2000).

\section{Retinoids and spermatogenesis}

In the testes of vitamin A-deficient rats, spermatogenesis was blocked at the A spermatogonia stage (Morales and Griswold, 1987) and retinoid supplementation retriggered spermatogenesis, which occurred concomitantly in all the tubules (Morales and Griswold, 1987). In such vitamin A-deficient rats, a high dose injection of retinoic acid strongly stimulated the proliferation of A spermatogonia and allowed their differentiation into B spermatogonia and then into spermatocytes, but not into spermatids (Van Pelt and de Rooij, 1991; Gaemers et al., 1998c). Repeated injections of retinoic acid were necessary for spermatogonia to reach the spermatid stage successfully (Van Pelt and de Rooij, 1991). Huang and Marshall (1983) suggested that vitamin A deficiency may delay spermiation. Therefore, retinoids appear indispensable to the proliferation and differentiation of A spermatogonia, during their transition to round and elongated spermatids and spermiation.

RAR- $\alpha$ mutant mice display germinal epithelium degeneration very similar to that of vitamin A-deficient animals (Lufkin et al., 1993). The location of RAR- $\alpha$ expression in the germ cells implies that retinoic acid exerts its effect on these cells via RAR- $\alpha$ (Akmal et al., 1997; Dufour and Kim, 1999). RXR- $\beta$ mutant mice are sterile, possibly because of deficient Sertoli cell functions (Kastner et al., 1996), as a gradual accumulation of lipids was observed in Sertoli cells well before the usual degeneration of the germinal epithelium that occurs in old males. In addition, in the seminiferous tubules, RXR- $\beta$ was expressed only in Sertoli cells (Kastner et al., 1996; Dufour and Kim, 1999).

Retinoids can also be harmful at excessively high doses. Hypervitaminosis $\mathrm{A}$ in rats reduces the testicular mass, creates lesions in the seminiferous epithelium and perturbs the rhythm of spermatogenesis (Biswas and Deb, 1965; Lamano Carvalho et al., 1978). As a result, the production of mature spermatozoa decreases and immature germ cells are extruded into the lumen of the seminiferous tubules. High doses of 13-cis retinoic acid, a very stable retinoid, block spermatogenesis completely (Sadek and AbdulMohsen, 1999).

\section{Retinoids and steroidogenesis}

In adult rats, vitamin A deficiency reduced basal testosterone secretion but testosterone secretion stimulated by exogenous $\mathrm{LH}$ remained similar to that of control rats (Appling and Chytil, 1981). This finding was supported by earlier reports of the atrophy of the accessory sex organs (prostate and seminal vesicles) and the female-type fine fur of vitamin A-deficient male rats (Thompson et al., 1964). Hypervitaminosis A or injection of 13-cis retinoic acid reduced the volume of testicular interstitial tissue and the mass of the seminal vesicles, and degraded the cytoplasm of Leydig cells (Biswas and Deb, 1965; Lamano Carvalho et al., 1978; Sadek and Abdul-Mohsen, 1999). These findings show that, in the same way as for spermatogenesis, both retinoid excess and retinoid deficiency are harmful to steroidogenesis.

The mechanism of action of retinoids is partly known. In adult rats, retinoids increased basal testosterone secretion in Leydig cell primary cultures but reduced this secretion when stimulated by LH (Chaudhary et al., 1989). These apparently contradictory findings were accounted for by the results of the studies conducted on cell lines that originated from Leydig cells (Lefèvre et al., 1994; Lee et al., 1999) showing that retinol and retinoic acid reduce the expression of $\mathrm{LH}$ receptors and greatly increase the expression of certain enzymes involved in steroidogenesis, such as P450 C17 $\alpha$-hydroxylase-C17-20 lyase and steroidogenic acute regulatory protein. Thus, the predominant negative effect of retinoids on $\mathrm{LH}$-stimulated testosterone secretion appears to be the reduction of the expression of $\mathrm{LH}$ receptors.

As with other specific functions, retinoids reduce basal testosterone production in fetal Leydig cells for a short period after testis differentiation (Livera et al., 2000) and, thus, the action of retinoic acid on Leydig cells differs between the adult and the fetus (Habert et al., 2001).

\section{Conclusion}

Retinoids are clearly involved in the regulation of testicular functions, and much progress has been made in understanding their mechanisms of action, although this understanding is far from complete. Research to date into the effects, mode of action and physiological involvement of retinoids in testicular functions has been conducted exclusively in rodents. It is important now to determine whether the therapeutic use of retinoids affects testicular functions in men. 
The authors wish to thank U. Reichert (Galderma R\&D), for the gift of synthetic analogues of the different RARs and RXRs, and M. Faro, for helpful technical assistance. G. Livera is the recipient of a fellowship from the Ministère de l'Education Nationale de la Recherche et de la Technologie.

\section{References}

Key references are identified by asterisks.

Akmal KM, Dufour JM and Kim KH (1997) Retinoic acid receptor alpha gene expression in the rat testis: potential role during the prophase of meiosis and in the transition from round to elongating spermatids Biology of Reproduction $\mathbf{5 6}$ 549-556

Akmal KM, Dufour JM, Vo M, Higginson S and Hee Kim K (1998) Liganddependent regulation of retinoic acid receptor $\alpha$ in rat testis: in vivo response to depletion and repletion of vitamin A Endocrinology 139 1239-1248

*Appling DR and Chytil F (1981) Evidence of a role for retinoic acid (vitamin A-acid) in the maintenance of testosterone production in male rats Endocrinology 108 2120-2123

Bardi G, Bottazzi C, Demori I and Palmero S (1999) Thyroid hormone and retinoic acid induce the synthesis of insulin-like growth factor-binding protein 4 in prepubertal pig Sertoli cells European Journal of Endocrinology 141 637-643

Bernardini S, Melino G, Saura F, Annicchiarico-Petruzzelli M, Motti C, Cortese C and Federici G (1997) Expression of co-factors (SMRT and Trip-1) for retinoic acid receptors in human neuroectodermal cell lines Biochemical and Biophysical Research Communications 234 278-282

Biswas NM and Deb C (1965) Testicular degeneration in rats during hypervitaminosis A Endokrinologie 49 64-69

Blaner WS, Galdieri M and Goodman DS (1987) Distribution and levels of cellular retinol- and cellular retinoic acid-binding protein in various types of rat testis cells Biology of Reproduction 36 130-137

Boulogne B, Levacher C, Durand P and Habert R (1999) Retinoic acid receptors and retinoid $\mathrm{X}$ receptors in the rat testis during fetal and postnatal development: immunolocalization and implication in the control of the number of gonocytes Biology of Reproduction $\mathbf{6 1}$ 1548-1557

Braun KW, Tribley WA, Griswold MD and Kim KH (2000) Folliclestimulating hormone inhibits all-trans-retinoic acid-induced retinoic acid receptor alpha nuclear localization and transcriptional activation in mouse Sertoli cell lines Journal of Biological Chemistry 275 4145-4151

*Cavazzini D, Galdieri M and Ottonello S (1996) Retinoic acid synthesis in the somatic cells of rat seminiferous tubules Biochimica et Biophysica Acta 1313 139-145

Chaudhary LR, Hutson JC and Stocco DM (1989) Effect of retinol and retinoic acid on testosterone production by rat Leydig cells in primary culture Biochemical and Biophysical Research Communications 158 400-406

Cupp A, Dufour J, Kim G, Skinner M and Kim K (1999) Action of retinoids on embryonic and early postnatal testis development Endocrinology $1402343-2352$

Davis JT and Ong DE (1995) Retinol processing by the peritubular cell from rat testis Biology of Reproduction 52 356-364

De Jong FH (1988) Inhibin Physiological Reviews 68 555-607

Deltour L, Haselbeck RJ, Ang HL and Duester G (1997) Localization of class I and class IV alcohol dehydrogenases in mouse testis and epididymis: potential retinol dehydrogenases for endogenous retinoic acid synthesis Biology of Reproduction 56 102-109

Dragnev KH, Rigas JR and Dmitrovsky E (2000) The retinoids and cancer prevention mechanisms Oncologist 5 361-368

Dufour JM and Kim KH (1999) Cellular and subcellular localization of six retinoid receptors in rat testis during postnatal development: identification of potential heterodimeric receptors Biology of Reproduction 61 1300-1308

Eskild W, Oyen O, Beebe S, Jahnsen T and Hansson V (1988) Regulation of mRNA levels for cellular retinol binding protein in rat Sertoli cells by cyclic AMP and retinol Biochemical and Biophysical Research Communications 152 1504-1510
Faraonio R, Galdieri M and Colantuoni V (1993) Cellular retinoic-acidbinding-protein and retinol-binding-protein mRNA expression in the cells of the rat seminiferous tubules and their regulation by retinoids European Journal of Biochemistry 211 835-842

Gaemers IC, van Pelt AMM, van Der Saag PT, Hoogerbrugge JW, Themmen APN and de Rooij DG (1997) Effect of retinoid status on the messenger ribonucleic acid expression of nuclear retinoid receptors $\alpha, \beta$ and $\gamma$ and retinoid $X$ receptors $\alpha, \beta$ and $\gamma$ in the mouse testis Endocrinology 138 1544-1551

Gaemers IC, van Pelt AMM, van der Saag PT, Hoogerbrugge JW, Themmen A and de Rooij DG (1998a) Differential expression pattern of retinoid X receptors in adult murine testicular cells implies varying roles for these receptors in spermatogenesis Biology of Reproduction 59 1351-1356

*Gaemers IC, Van Pelt AM, Themmen AP and De Rooij DG (1998b) Isolation and characterization of all-trans-retinoic acid-responsive genes in the rat testis Molecular Reproduction and Development 50 1-6

Gaemers IC, Sonneveld E, van Pelt AM, Schrans BH, Themmen AP, van der Saag PT and de Rooij DG (1998c) The effect of 9-cis-retinoic acid on proliferation and differentiation of $\mathrm{A}$ spermatogonia and retinoid receptor gene expression in the vitamin A-deficient mouse testis Endocrinology 139 4269-4276

Galdieri M and Nistico L (1994) Retinoids regulate gonadotropin action in cultured rat Sertoli cells Biology of Reproduction 50 171-177

Galdieri M, Caporale C and Adamo S (1986) Calcium-, phospholipiddependent protein kinase activity of cultured rat Sertoli cells and its modifications by vitamin A Molecular and Cellular Endocrinology $\mathbf{4 8}$ 213-220

Gerster H (1997) Vitamin A-functions, dietary requirements and safety in humans International Journal of Vitamin and Nutrition Research $\mathbf{6 7}$ 71-90

*Giguère V (1994) Retinoic acid receptor and cellular retinoid binding proteins: complex interplay in retinoid signalling Endocrine Reviews 15 $61-79$

Guma FC and Bernard EA (1994) Effects of retinol on glycoprotein synthesis by Sertoli cells in culture: dolichyl phospho mannose synthase activation International Journal of Andrology 17 50-55

Guo X, Morris P and Gudas L (2001) Follicle-stimulating hormone and leukemia inhibitory factor regulate Sertoli cell retinol metabolism Endocrinology 142 1024-1032

Habert R, Lejeune H and Saez JM (2001) Origin, differentiation and regulation of fetal and adult Leydig cells Molecular and Cellular Endocrinology 179 47-74

Hardy DO, Ge RS, Catterall JF, Hou YT, Penning TM and Hardy MP (2000) Identification of the oxidative 3alpha-hydroxysteroid dehydrogenase activity of rat Leydig cells as type II retinol dehydrogenase Endocrinology 141 1608-1617

Hercberg S, Preziosi P, Galan P, Devanlay M, Keller H, Bourgeois C, Potier de Courcy G and Cherouvrier F (1994) Vitamin status of a healthy French population: dietary intakes and biochemical markers International Journal of Vitamin and Nutrition Research 64 220-232

Huang HF and Marshall GR (1983) Failure of spermatid release under various vitamin A states - an indication of delayed spermiation Biology of Reproduction 28 1163-1172

Huang HFS, Li MT, Pogach LM and Qian L (1994) Messenger ribonucleic acid of rat testicular retinoic acid receptors: developmental pattern, cellular distribution and testosterone effect Biology of Reproduction $\mathbf{5 1}$ 541-550

Kastner P, Mark M, Mark L, Dierich A and Chambon P (1996) Abnormal spermatogenesis in RXRß mutant mice Gene Development 10 80-92

Kim KH and Griswold MD (1990) The regulation of retinoic acid receptor mRNA levels during spermatogenesis Molecular Endocrinolology 4 1679-1688

Klamt F, Dal-Pizzol F, Ribeiro NC, Bernard EA, Benfato MS and Moreira JC (2000) Retinol-induced elevation of ornithine decarboxylase activity in cultured rat Sertoli cells is attenuated by free radical scavenger and by iron chelator Molecular and Cellular Biochemistry 208 71-76

Kurlandsky SB, Gamble MV, Ramakrishnan R and Blaner WS (1995) Plasma delivery of retinoic acid to tissues in the rat Journal of Biological Chemistry $27017850-17857$ 
Lamano Carvalho TL, Lopes RA, Azoubel R and Ferreira AL (1978) Morphometric study of the reversibility of testicle alterations in rats submitted to hypervitaminosis A International Journal of Vitamin and Nutrition Research $48316-324$

Lampron C, Rochette-Egly C, Gorry P, Dolle P, Mark M, Lufkin T, LeMeur $\mathbf{M}$ and Chambon $\mathbf{P}$ (1995) Mice deficient in cellular retinoic acid binding protein II (CRABPII) or in both CRABPI and CRABPII are essentially normal Development 121 539-548

Lee HK, Yoo MS, Choi HS, Kwon HB and Soh J (1999) Retinoic acids upregulate steroidogenic acute regulatory protein gene Molecular and Cellular Endocrinology 148 1-10

Lefèvre A, Rogier E, Astraudo C, Duquenne C and Finaz C (1994) Regulation by retinoids of luteinizing hormone/chorionic gonadotropin receptor, cholesterol side-chain cleavage cytochrome P-450, 3及hydroxysteroid dehydrogenase/ $\Delta 5$-4-isomerase and $17 \alpha$-hydroxylase/C1720 lyase cytochrome P-450 messenger ribonucleic acid levels in the K9 mouse Leydig cell line Molecular and Cellular Endocrinology 106 31-39

Leo C, Yang X, Liu J, Li H and Chen JD (2001) Role of retinoid receptor coactivator pockets in cofactor recruitment and transcriptional regulation Journal of Biological Chemistry 27623 127-23 134

* Livera G, Rouiller-Fabre V, Durand P and Habert R (2000) Multiple effects of retinoids on the development of Sertoli, germ and Leydig cells of fetal and neonatal rat testis in culture Biology of Reproduction 62 1303-1314

Livera G, Rouiller-Fabre V and Habert R (2001) Retinoid receptors involved in the effects of retinoic acid on rat testis development Biology of Reproduction 64 1307-1314

Lopez-Fernandez LA and del Mazo J (1997) The cytosolic aldehyde dehydrogenase gene (Aldh1) is developmentally expressed in Leydig cells FEBS Letters $\mathbf{4 0 7} 225-229$

Lufkin T, Lohnes D, Mark M, Dierich A, Gorry P, Gaub MP, Le Meur M and Chambon P (1993) High postnatal lethality and testis degeneration in retinoic acid receptor $\alpha$ mutant mice Developmental Biology 90 7225-7229

Marinos E, Kulukussa M, Zotos A and Kittas C (1995) Retinoic acid affects basement membrane formation of the seminiferous cords in 14-day male rat gonads in vitro. Differentiation 59 87-94

Mora JO, Gueri M and Mora OL (1998) Vitamin A deficiency in Latin America and the Caribbean: an overview Revue of Panama Salud Publica 4 178-186

Morales C and Griswold D (1987) Retinol-induced synchronization in seminiferous tubules of the rat Endocrinology 121 432-434

Page KC, Heitzman DA and Chernin MI (1996) Stimulation of c-jun and Cmyb in rat Sertoli cells following exposure to retinoids Biochemical and Biophysical Research Communications 222 595-600

Ricci G, Catizone A, Scarcella MF and Galdieri M (1999) Vitamin A modulation of basement membrane production by purified testicular myoid cells Experimental Cell Research 249 102-108

Rosselli M and Skinner MK (1992) Developmental regulation of Sertoli cell aromatase activity and plasminogen activator production by hormones, retinoids and the testicular paracrine factor, PModS Biology of Reproduction 46 586-594

Sadek IA and Abdul-Mohsen MH (1999) Long-term administration of vitamin A and the process of spermatogenesis Eastern Mediterranean Health Journal 5 123-129

Samy ET, Li JC, Grima J, Lee WM, Silvestrini B and Cheng CY (2000) Sertoli cell prostaglandin D2 synthetase is a multifunctional molecule: its expression and regulation Endocrinology 141 710-721

Schmitt C and Ong D (1993) Expression of cellular retinol-binding protein and lecithin-retinol acyltransferase in developing rat testis Biology of Reproduction 49 972-979

Sigillo F, Guillou F, Fontaine I, Benahmed M and Le Magueresse-Battistoni B (1999) In vitro regulation of rat Sertoli cell transferrin expression by tumor necrosis factor alpha and retinoic acid Molecular and Cellular Endocrinology 148 163-170

Skinner M, Schlitz S and Anthony C (1989) Regulation of Sertoli cell differentiated function: testicular transferrin and androgen-binding protein expression Endocrinology 124 3015-3024

Thompson JN, Howell JMC and Pitt GAJ (1964) Vitamin A and reproduction in rats Proceedings of the Royal Society of Medicine 159 510-535

Van Pelt A and de Rooij D (1991) Retinoic acid is able to reinitiate spermatogenesis in vitamin A deficient rats and high replicate doses support the full development of spermatogenic cells Endocrinology $\mathbf{1 2 8}$ 697-704

Wei LN, Farooqui $\mathbf{M}$ and Hu X (2001) Ligand-dependent formation of retinoid receptors, receptor-interacting protein 140 (RIP140), and histone deacetylase complex is mediated by a novel receptor-interacting motif of RIP140 Journal of Biological Chemistry 276 16107-16112

Wolbach SB and Howe PR (1925) Tissue changes following deprivation of fat-soluble A vitamin Journal of Experimental Medicine 42 753-777

Zhai Y, Sperkova Z and Napoli J (2001) Cellular expression of retinal dehydrogenase types 1 and 2: effects of vitamin A status on testis mRNA Journal of Cellular Physiology 186 220-232

Zheng WL, Bucco RA, Schmit MC, Wardlaw SA and Ong DE (1996) Localisation of cellular retinoic acid-binding protein (CRABP) II and CRABP in developing rat testis Endocrinology 137 5028-5035

Zhuang YH, Blauer M, Ylikomi T and Tuohimaa P (1997) Spermatogenesis in the vitamin A-deficient rat: possible interplay between retinoic acid receptors, androgen receptor and inhibin alpha-subunit Journal of Steroid Biochemistry and Molecular Biology 60 67-76 